\title{
Dinámica de la acumulación capitalista en el territorio correntino. Una aproximación al sector rural.*
}

\author{
Dynamics of capitalist accumulation in the correntino territory. An approach to \\ the rural sector.
}

Marcelo Graciosi**

\section{Resumen}

Este escrito es un adelanto de un proyecto de investigación en curso sobre la dinámica social en la provincia de Corrientes en las últimas décadas. Esta es leída a través del 'lente' de ciertas categorías que nos remiten a Marx: modo de producción, formación social, acumulación, conflictos sociales y lucha de clases. Esto significa que no observamos a los 'sujetos' o a los 'actores económicos', ni a los 'agentes sociales' y sus 'representaciones' individuales o colectivas. El propósito particular es caracterizar la formación social correntina con las tensiones propias de la etapa actual y su contraste con la década de sesenta. Especialmente, el interés está puesto en analizar la forma de acumulación, los conflictos y las luchas que se desarrollan en el ámbito rural.

\section{Abstract}

This writing is an advance of an investigation proyect in a course about the social dynamic in the province of Corrientes in the last decades. It is read seen through the Marx's categories: mode of production, social formation, accumulation, social conflicts and clases struggles. This means taht we do not observe the "Subjects" or "economics actors", neither the "social agents" and their individual or collective representations. The main purpose is to analize the social formation of the province with its own conflicts of nowadays and its contrast with the $60^{\prime} \mathrm{S}$. The interest is on the accumulation, conflicts and struggles that take part in the "rural context".

* Artículo recibido el 10 de Septiembre de 2015. Aceptado el 5 de Diciembre de 2015.

** Adjunto de Sociología General. Facultad de Humanidades. UNNE Miembro del EllCyT. (Espacio Interdisciplinario de Investigación sobre Conflicto y Territorio). Correo electrónico: marcgraciosi@hotmail.com 


\section{Palabras clave}

Formación social - Acumulación - Área rural

\section{Keywords}

Social formation - accumulation - rural

\section{Introducción}

El presente trabajo tiene por objetivo indagar sobre la dinámica de la acumulación capitalista en el territorio correntino, particularmente, la dinámica agropecuaria y forestal tomando como contraste la década de 60 y la situación actual. Tomamos la situación del sector agropecuario y forestal por el peso relativo que tiene este sobre el Producto Bruto Interno de la provincia.

Este trabajo se inscribe en el marco de un programa de investigación que apunta a estudiar el movimiento de la sociedad en la región Gran Chaco a partir de categorías como formación social, acumulación, conflicto, poder, violencia, entre otros.

El problema que tomamos para indagar es el movimiento de la formación social correntina atendiendo a las variaciones que puedan registrarse en el modo de acumulación. Esto implica aproximarnos a las tensiones que se evidencian en la forma que asume la acumulación capitalista en la región, en particular, las variaciones que se pueden observar en la estructura social agropecuaria, entendiendo que esta se inscribe en una trama compleja, donde por una parte tenemos una tendencia a una explotación capitalista poco dinámica, y por otra parte emergen nuevos nichos de negocios en el territorio correntino que alteran el 'paisaje natural'.

La metodología de trabajo implicó desarrollar un marco conceptual desde el cual se plantearon los objetivos, la problematización, los interrogantes y la hipótesis. En términos metodológicos, fue clave construir un cuadro mínimo de la forma en que opera el capital agropecuario y forestal, realizando un análisis comparativo de los sesenta con los procesos actuales. Así, pudimos ver, por ejemplo, que en la década de sesenta en la provincia de Corrientes la explotación ganadera estaba concentrada en muy pocas manos, con escaso 
desarrollo técnico en la producción, lo que generaba baja demanda de fuerza de trabajo, mientras que la relativa modernización ganadera implicó una reducción del tamaño de las unidades productivas con la aparición de nuevas tecnologías; sin embargo, este cambio en la producción no alteró el grado de empleo de la fuerza de trabajo. Para la elaboración de este cuadro de la estructura agropecuaria, seguimos el trabajo de Daniel Slutzky. Asimismo, complementamos el trabajo de Slutzky con diversas fuentes escritas -prensa local, informes de investigadores, entrevistas- para dar cuenta de los procesos de acumulación recientes en la provincia de Corrientes.

Los cuadros que utilizamos sirvieron para observar la conformación de la estructura económica agropecuaria en un período dado, y luego comparar su evolución. Dado que la presente investigación es parte de un proyecto un curso, los datos deben ser ampliados.

La hipótesis es que detrás de lo que usualmente se nombra como desarrollo de la economía correntina subyacen nuevas formas de acumulación. $Y$ es admisible considerar que esta asume rasgos particulares a partir de una nueva comunidad de negocios que emerge en el territorio correntino. En este sentido, parte de nuestra hipótesis es que el territorio correntino aparece como un espacio a ser apropiado por capitales nacionales y transnacionales que tienen el poder para desplazar a fracciones menores de burguesía o que buscan consolidar nuevas formas de extraer plusvalor. Estas nuevas formas de operar probablemente impliquen formas de acumulación por desposesión.

Algunos de los interrogantes que permitieron diseñar y avanzar en el proceso de investigación fueron: ¿Cuál es la dinámica de la acumulación en Corrientes en torno a la actividad agropecuaria y forestal? ¿Qué variaciones podemos observar en la dinámica actual de acumulación respecto a la forma que esta tenía en las décadas de 60 y 70 del siglo XX? ¿Cómo influye la forma en que opera el capital sobre las condiciones de vida de la población?

Parte de la conclusión -provisoria- a que hemos arribado, luego de contrastarla con los diversos datos que obtuvimos, es que efectivamente existen variaciones en las formas de explotación capitalista. Tal es el caso, por ejemplo, de todo el negocio forestal, el cual altera las condiciones en que la población reproduce sus vidas. Es por ello que pudimos corroborar la existencia de violencia económica y extraeconómica actuando en la dinámica de la acumulación capitalista en el sector agropecuario y forestal.

También es parte de la conclusión reconocer de qué modo lo que 
usualmente nombramos con la palabra 'Estado' se presenta en múltiples ocasiones como un vector de la acumulación capitalista, liberando zonas para la explotación agropecuaria y forestal, ejerciendo control sobre la conducta de la población o, en otros casos, ejerciendo una violencia directa para desplazar el cuerpo de los individuos que impiden la generación de plusvalía. Tal descripción abona la concepción que sustenta este trabajo, la cual considera que el capital dibuja las condiciones de vida de la población, y este dibujo se asemeja a un tapiz, donde en su exterior vemos una imagen bucólica de una sociedad armónica e indiferenciada, mientras que la trama interna que sostiene dicha imagen está construida con formas visibles e invisibles de violencia.

\section{Marco Conceptual}

Este trabajo parte de la reivindicación de la discusión teórica como elemento constructivo de la investigación. Las preguntas, las hipótesis, y los métodos con que nos vamos a movilizar en la investigación están fundidos con la potencia analítica de las categorías conceptuales con que operamos, sobre todo, el objetivo de la investigación está enmarcado en la orientación teórica que la sustenta. ${ }^{1} \mathrm{Y}$ el punto de partida teórico que a su vez consideramos pertinente tomar es el trazo grueso que aportaron Marx y Engels, por una parte, $y$, por otra parte, pensadores que continúan sus líneas de análisis: Althusser, Harvey, entre otros.

A partir de Marx y Engels entendemos que lo social refiere a un conjunto de relaciones sociales que tienen un carácter material. Dicha materialidad está cargada de relaciones de fuerza. Como Marx y Engels plantean en La Ideología Alemana, el mundo efectivo no se construye desde el reino de las ideas, sino que es el individuo en sus relaciones materiales con otros individuos quien desarrolla una existencia atravesada por contradicciones, entre ellas, la contradicción entre capital/trabajo. (Marx y Engels, 1974). Por su parte, Marx considera que las relaciones sociales no representan formas de intersubjetividad, sino relaciones que asignan una función necesaria tanto a los hombres como a las cosas. Este autor expone su tesis central al afirmar que las relaciones sociales conforman una trabazón, una estructura que se construye a partir del conjunto de relaciones sociales de producción:

\footnotetext{
$1 \quad$ Ruth Sautu en su Manual de metodología ha destacado la importancia de la teoría y la discusión teórica como fuente de inspiración de la imaginación sociológica y en la construcción del diseño de la investigación empírica (Sautu et al., 2005).
} 
Mi primer trabajo, emprendido para resolver las dudas que me asaltaban, fue una revisión crítica de la filosofía hegeliana del derecho. Mi investigación desembocaba en el resultado de que, tanto las relaciones jurídicas como las formas de Estado no pueden comprenderse por sí mismas ni por la llamada evolución general del espíritu humano, sino que radican, por el contrario, en las condiciones materiales de vida cuyo conjunto resume Hegel, siguiendo el precedente de los ingleses y franceses del siglo XVIII, bajo el nombre de «sociedad civil», y que la anatomía de la sociedad civil hay que buscarla en la Economía Política en la producción social de su vida, los hombres contraen determinadas relaciones necesarias e independientes de su voluntad, relaciones de producción, que corresponden a una determinada fase de desarrollo de sus fuerzas productivas materiales. El conjunto de estas relaciones de producción forma la estructura económica de la sociedad la base real sobre la que se levanta la superestructura jurídica y política y a la que corresponden determinadas formas de conciencia social. El modo de producción de la vida material condiciona el proceso de la vida social, política y espiritual en general. Al cambiar la base económica, se revoluciona, más o menos rápidamente, toda la inmensa superestructura erigida sobre ella. Cuando se estudian esas revoluciones, hay que distinguir siempre entre los cambios materiales ocurridos en las condiciones económicas de producción y que pueden apreciarse con la exactitud propia de las ciencias naturales, y las formas jurídicas, políticas, religiosas, artísticas o filosóficas, en una palabra, las formas ideológicas en que los hombres adquieren conciencia de este conflicto y luchan por resolverlo (Marx, 1974: $3)$.

Tomamos como parte fundante de nuestro marco conceptual esta concepción que plantea la existencia de relaciones sociales cargadas de materialidad entre los individuos. Materialidad que está mediada por las condiciones sociales que se producen a nivel estructural y superestructural. Estas mediaciones son dinámicas:

Según la concepción materialista de la historia, el factor que en última instancia determina la historia es la producción y la reproducción de la vida real. $\mathrm{Ni}$ Marx ni yo hemos afirmado nunca más que esto. Si alguien lo tergiversa diciendo que el factor económico es el único determinante, convertirá aquella tesis en una frase vacua, abstracta, absurda. La situación económica es la base, pero los diversos factores de la superestructura que sobre ella se levanta -las formas políticas de la lucha de clases y sus resultados, las Constituciones que, después de ganada una batalla, redacta la clase triunfante, etc., las formas jurídicas, e incluso los reflejos de todas estas luchas reales en el cerebro de los participantes, las teorías políticas, jurídicas, filosóficas, las ideas religiosas y el desarrollo ulterior de éstas hasta convertirlas en un sistema de dogmas- ejercen también su influencia sobre el curso 
de las luchas históricas y determinan, predominantemente en muchos casos, su forma. Es un juego mutuo de acciones y reacciones entre todos estos factores, en el que, a través de toda la muchedumbre infinita de casualidades (es decir, de cosas y acaecimientos cuya trabazón interna es tan remota o tan difícil de probar, que podemos considerarla como inexistente, no hacer caso de ella), acaba siempre imponiéndose como necesidad el movimiento económico. De otro modo, aplicar la teoría a una época histórica cualquiera sería más fácil que resolver una simple ecuación de primer grado (Marx y Engels, 1974 b).

En la dinámica social, no debemos subestimar el papel que cumple la denominada superestructura; tanto las leyes como las concepciones sociales arraigadas en diferentes sectores de la población correntina han jugado, por ejemplo, un rol clave a la hora de legitimar la instalación de nuevos modos productivos. La base económica -la capacidad del poder económico de ejercer la violencia sorda de las relaciones económicas- (Marx, 2005: 899) es determinante en última instancia, pero la cultura, las instituciones sociales, las leyes, el juego de la política intervienen incidiendo en el curso de la historia.

La teoría de Marx y Engels, anteriormente esbozada, nos posibilita pasar de una descripción de la sociedad -decir, por ejemplo, que en toda sociedad existen industrias, campos cultivados, correos, escuelas, ejército, policía, leyes, corrientes ideológicas, etc.- a plantear cuál es la organización de estos elementos en las diferentes estructuras (económica, jurídico-política e ideológica) y la determinación del papel que cada una de esas estructuras desempeña en la sociedad nos permite pasar de la descripción al conocimiento de una realidad social.

Es interesante tomar el aporte de Louis Althusser, quien ha puesto énfasis justamente en la diferencia entre papel dominante y determinación en última instancia. En el caso del modo de producción servil, por ejemplo, no son las leyes económicas las que aseguran que los señores feudales se sigan haciendo con el excedente que es producido a partir de la explotación de la tierra. Se necesita una serie de factores superestructurales, la activa participación de leyes y elementos ideológicos. Estos factores cumplen un papel dominante, más allá de la determinación en última instancia (Althusser, 1987: 323).

Es importante, por otra parte, rescatar un concepto estrechamente vinculado con el planteo teórico anterior: se trata del concepto de formación social. Con lo que habitualmente nos encontramos cuando estudiamos una realidad social histórica no es con un modo productivo abstracto, sino con una 
formación social determinada. ¿Qué implica esta cuestión? Marx estudia en El Capital un modo de producción abstracto, el modo de producción capitalista moderno y la Inglaterra de la segunda mitad del siglo XIX sirven a modo de ilustración, atendiendo a que Inglaterra es el país donde se presentaban en forma madura las relaciones capitalistas.

La categoría modo de producción nos permite pensar en la sociedad global como una totalidad orgánica en sus diferentes etapas (modo esclavista, modo asiático, modo feudal, modo capitalista). El concepto de formación social refiere a una totalidad social concreta, históricamente determinada, estructurada a partir de la forma en que se combinan las diferentes relaciones de producción que coexisten a nivel de la estructura económica. La Rusia analizada por Lenin en su artículo sobre El impuesto de las especies es un ejemplo de la combinación de diferentes sistemas económicos. Lenin menciona la combinación de una economía campesina patriarcal, con la pequeña producción mercantil (esta categoría comprende la mayor parte de los campesinos que venden trigo), el capitalismo privado, el capitalismo de Estado y el socialismo. Otro ejemplo es la Francia analizada por Marx en El XVIII Brumario. En ella se encuentra una combinación de diferentes modos de producción de bienes materiales: feudal, patriarcal, pequeño-mercantil y capitalista (Althusser, 1987: 341). Ahora bien, estas diversas relaciones de producción que coexisten en una sociedad históricamente determinada no lo hacen en forma anárquica ni aislada de otras: una de ellas ocupa una situación dominante, imponiendo a las demás sus propias leyes de funcionamiento.

De lo expuesto anteriormente se deduce que la dominación de un tipo determinado de relaciones de producción no hace desaparecer en forma automática todas las otras relaciones de producción: estas pueden seguir existiendo, aunque modificadas y subordinadas a las relaciones de producción dominantes.

Podemos afirmar, por ejemplo, que desde la época de la conquista los países de América Latina han estado sometidos al sistema capitalista mundial, en un comienzo bajo las forma de capitalismo comercial y luego a través de relaciones de producción propiamente capitalistas -en la mayor parte de ellos-; pero afirmar que este sistema capitalista mundial domina no significa negar que existían y que todavía existen, en forma muy difundida, relaciones precapitalistas de producción, relaciones de producción que se acercan a las de la comunidad primitiva en algunos lugares aislados, relaciones semiserviles en 
muchas zonas campesinas y una difusión bastante grande de la pequeña producción artesanal. Si pensamos en nuestro objeto en particular, es probable que nos encontremos con formas artesanales de producción que son desplazadas por formas actuales de explotación capitalista.

Finalmente, no podemos perder de vista que es la lucha de clases en las formaciones sociales lo que constituye el 'motor de la historia'. Por ello, cuando pensamos en las combinaciones históricas concretas, nos vamos a encontrar siempre con un estado de fuerzas en pugna dado por las alianzas y enfrentamientos entre fracciones de clase de una formación social. En el caso de Corrientes tendremos a nuevos estancieros que desplazan a estancieros tradicionales en la medida que pueden sostener la rentabilidad del sector.

\section{Formas de acumulación: acumulación originaria, continua, por desposesión}

Para Marx el capital no es una categoría económica, sino un concepto que alude a un proceso social, proceso que, subordinando la producción a una lógica ajena a la mera satisfacción de necesidades, se sostiene y recrea en vínculos de dominio y subordinación entre seres humanos.

En el Capítulo XXIV, ubicado en la Sección Séptima del Tomo I de El Capital, Marx discute la llamada "acumulación originaria". El autor parte del hecho de que para cualquier período de tiempo el proceso de acumulación propiamente dicho- se origina en que cierta cantidad de capital preacumulado haya sido lanzada al proceso de producción. La producción capitalista supone entonces cierta acumulación "originaria" o "primitiva". Dicha acumulación originaria consistió básicamente en la constitución de una fuerza de trabajo obligada a venderse en un naciente mercado laboral. "La relación del capital consiste en la escisión entre los trabajadores y la propiedad sobre las condiciones de realización del trabajo". Las precondiciones de acumulación capitalista refieren a la creación de un sector de la población sin otros medios de vida que su propia fuerza de trabajo para vender en el naciente mercado laboral. (Marx, 2005: 899). Esta escisión se realizó de manera forzada, bajo la coacción de leyes sanguinarias que el autor describe en el mencionado capítulo.

La reproducción del capital, dice Marx, implica la reproducción de este divorcio entre obreros libres y la propiedad de sus condiciones de existencia. Los obreros, desde esa perspectiva, solo pueden reproducirse en la medida en que se vendan como una mercancía más en el mercado. Cabe resaltar que no podemos pensar en acumulación originaria sin conectar con la creación de un 
mercado global ni con la explotación de nuevos territorios, es decir, sin vincular a una transición general del feudalismo al capitalismo enmarcada en la constitución de un capitalismo mercantil a escala mundial que se produce de diferentes maneras, expansión por medio de la guerra, la conquista, el saqueo, la explotación de los mares, la explotación de las materias primas, de la fuerza excedentaria de trabajo, etc.

El concepto de escisión entre productores y sus condiciones de reproducción es central. Ahora bien, esta separación no se detiene, sino que se reproduce constantemente a una escala ampliada. La diferencia entre acumulación originaria y la acumulación continua es que mientras la primera produce esta separación entre las condiciones de trabajo y el sujeto, la segunda la reproduce en forma ampliada, -acumulando relaciones sociales. Marx enfatiza que, mientras la acumulación propiamente dicha depende fundamentalmente de "la coerción sorda de las relaciones económicas que pone su sello a la dominación del capitalista sobre el obrero", la acumulación primitiva lo hace de la separación impuesta principalmente a través de la "fuerza directa extraeconómica" (De Angelis, 2012: 8-9). La acumulación primitiva es para Marx un proceso social instigado por algún actor social (el Estado, alguna clase social particular, etc.) y dirigido a la población que tiene alguna forma de acceso directo a los medios de producción.

Rosa Luxemburg, a su vez, sostiene que la acumulación es imposible si nos movemos exclusivamente en el ámbito de una economía capitalista cerrada. Según esta autora, la acumulación continua o ampliada se da por el contacto con el entorno social no-capitalista. Si el capitalismo no ha muerto ya, se debe únicamente a que ha tenido la posibilidad de ir invadiendo esas sociedades no capitalistas de su entorno (Luxemburg, 2011: 355). El capitalismo necesita estamentos sociales no capitalistas como mercado para obtener plusvalía, tanto como fuente de medios de producción, así como de reserva de mano de obra. El capitalismo tiene que librar siempre y en todas partes una batalla para aniquilar cualquier forma histórica de economía natural, precapitalista o arcaizante que encuentre. En este aspecto, la violencia extraeconómica vuelve a hacerse presente en la reproducción ampliada del capitalismo mundial (Luxemburg; 2011: 368).

En consonancia con esta lectura de Rosa Luxemburg, De Angelis plantea que la llamada acumulación originaria no es un proceso que no pueda volver a suceder, dado que su factor principal es la escisión entre los productores y la propiedad de su modo de vida; de acuerdo con ello, aun en el capitalismo maduro, este proceso se puede volver a suceder cada vez que el capital lo 
requiera. La violencia directa se utiliza, por ejemplo, para detener procesos donde los trabajadores avancen sobre la propiedad de los medios de producción.

Un autor que se ha convertido en referencia obligada para hablar de acumulación es el geógrafo inglés David Harvey. Este retoma los trabajos de Lenin y Luxemburg, por una parte, y de Henry Lefebvre, por otra. El concepto del cual parte es que la incapacidad de acumular a través de la reproducción ampliada sobre una base sustentable ha sido acompañada por crecientes intentos de acumular por desposesión. En la fase actual del capitalismo marcada -por la crisis de los años 70-, Harvey encuentra una variación a la que denomina nuevo imperialismo. La crisis del sistema está expresada por la limitación para realizar ajustes espacio-temporales efectivos. La sobreacumulación en un determinado sistema territorial supone un excedente de trabajo (creciente desempleo) y excedente de capital (expresado como una sobreabundancia de mercancías en el mercado que no pueden venderse sin pérdidas, como capacidad productiva inutilizada, y/o excedentes de capital dinero que carecen de oportunidades de inversión productiva y rentable). De este modo, si no se producen devaluaciones sistémicas -e incluso la destrucción- de capital y de fuerza de trabajo, deben encontrarse maneras de absorber estos excedentes. La expansión geográfica y la reorganización espacial cumplen esta función. Harvey parte del análisis de Rosa Luxemburg mencionado anteriormente acerca de la relación entre zonas desarrolladas y zonas no desarrolladas por el capital. Así, el capital global compulsivamente actualiza formas de violencia extraeconómica sobre nuevos espacios sociales. En este aspecto, considera que no hay que relegar la idea de acumulación basada en la depredación, el fraude y la violencia a una 'etapa originaria', o, como en el caso de Luxemburgo, la violencia no puede ser tomada como algo 'exterior' al sistema capitalista. Pero a través de una revisión general del rol permanente y de la persistencia de prácticas depredadoras de acumulación 'primitiva' u 'originaria' a lo largo de la geografía histórica de la acumulación capitalista, Harvey introduce la noción teórica de acumulación por desposesión. La violencia y el despojo son procedimientos constantes del capital en la medida en que para generar nuevos negocios tiene que desposeer a los sujetos de su hábitat, de sus derechos, de sus tierras, de su movilidad, de su propia corporalidad.

Finalmente, lo que ciñe a estas reflexiones sobre la acumulación es que el capital opera con múltiples formas de violencia cuando se reproduce, y esta 
reproducción no puede pensarse por fuera de estas formas de violencia. La lucha de clases es justamente esto, el desarrollo de diversas formas visibles e invisibles de violencia que articulan o desarticulan relaciones sociales que afectan a los sujetos.

\section{La lógica de acumulación del sector rural en la década de sesenta y setenta}

En primer lugar, exponemos cuál era la estructura agraria en la década que va de los años sesenta a los setenta en la provincia de Corrientes. Como dijimos en la introducción, Corrientes está signada por la importancia de actividades de carácter agropecuario. En la década de los sesenta básicamente estas actividades se circunscribían a lo agropecuario -en la actualidad cobra peso la forestación-, registrándose un bajo nivel de desarrollo de actividades industriales: "...La dinámica económica de Corrientes gira alrededor del sector agropecuario que para 1969 contribuye con el 31,23\% del Producto Bruto Provincial, valor que duplica al aportado por la industria manufacturera (15\%), el comercio (15,91\%) y los servicios gubernamentales $(15,0 \%)$..." (Slutzky, 2011: 218). Cabe destacar la necesidad futura de avanzar en los estudios sobre otros sectores de la burguesía que operaba en el territorio correntino, como la industria textil, la construcción, etc.; para componer un cuadro general de la fuerza productiva imperante.

Siguiendo el trabajo de Daniel Slutzky sobre la estructura productiva de la provincia de Corrientes, podemos registrar que, en la década que va del sesenta al setenta, la agricultura mantiene los índices de producción y explotación de la tierra, y en producciones como el tabaco o el algodón evidencia un franco deterioro (Slutzky, 2011: 198). Este panorama lo podemos observar en el siguiente cuadro que también muestra el estancamiento de las zonas agrícolas respecto al aumento de la ganadería en esta década.

\begin{tabular}{|c|c|c|c|c|c|c|c|c|}
\hline \multirow{3}{*}{ Año } & \multicolumn{8}{|c|}{ Superficie utilizada en la reproducción social } \\
\hline & \multicolumn{2}{|l|}{ Ocupada } & \multicolumn{2}{|c|}{ Cultivada } & \multicolumn{2}{|c|}{ Forestada } & Vacunos & Ovinos \\
\hline & ha & $\%$ & ha & $\%$ & ha & $\%$ & \multicolumn{2}{|c|}{ Número de cabezas } \\
\hline 1960 & 6.208 .182 & 100.0 & 211.539 & 3.4 & - & - & 2.887 .850 & 2.169 .707 \\
\hline 1969 & 7.607.159 & 100.0 & 211.478 & 2.8 & 31.478 & 0.4 & 3.950 .001 & 3.054.631 \\
\hline
\end{tabular}


Fuente: INDEC.

Si nos atenemos a la forma que tiene la propiedad de la tierra, nos encontramos con cierta fisonomía social de Corrientes. En cierta medida, por esta época, los dueños de la tierra se corresponden con grupos que detentan el poder de administrar el territorio. La pregunta que corresponde hacernos en este caso es ¿en qué medida este proceso de acumulación de capital dibuja las condiciones de vida de la población? Si nos fijamos, por ejemplo, en la explotación ganadera que es dominante en esta etapa, esta generaba poca ocupación de mano de obra rural (los campesinos correntinos de la zona norte, por ejemplo, se sostenían en una economía de subsistencia, con poca o nula propiedad y uso de la tierra, y con trabajo rentado ocasional).

Si analizamos la relación entre esta producción latifundista y los procesos demográficos, notamos que en la década que va de 1960 a 1970 la provincia tiene un crecimiento poblacional del orden del 5\%, al mismo tiempo que sufre una emigración de alrededor de 91.800 personas que se trasladan al Chaco, Misiones y acabada la absorción de brazos para las industrias del tanino y textiles de estas provincias, los trabajadores correntinos tienen como segunda opción de destino a la ciudad de Rosario, la Capital Federal y el Gran Buenos Aires. En la provincia, el campo se despobló, acrecentándose la población urbana, principalmente de ciudades como Goya y Capital, donde los excampesinos pasan a engrosar un proletariado subocupado.

El siguiente cuadro brinda información sobre la disminución de la población rural como la contracara del crecimiento de los terratenientes:

Población urbana y rural 1960 y 1970 . Corrientes.

\begin{tabular}{|l|l|l|l|l|l|l|}
\hline \multirow{2}{*}{ Año } & \multicolumn{4}{|l|}{ Total } & Urbana & \multicolumn{2}{l|}{ Rural } \\
\cline { 2 - 8 } & $\mathrm{N}^{\circ}$ & $\%$ & $\mathrm{~N}^{\circ}$ & $\%$ & $\mathrm{~N}^{\circ}$ & $\%$ \\
\hline 1960 & 533.021 & 100.0 & 247.312 & 46.4 & 285.889 & 53.6 \\
1970 & 564.147 & 100.0 & 356.703 & 63.3 & 207.444 & 36.7 \\
\hline
\end{tabular}

Fuente: INDEC.

Este cuadro corrobora el análisis anterior: la población rural disminuye abruptamente del $53 \%$ al $36 \%$ sobre el total. Esta migración del campo a la ciudad está inscripta también en una lógica de producción agraria donde el crecimiento en la producción no alcanza a absorber el aumento vegetativo de la 
población, esto ocurre incluso en zonas tabacaleras de ocupación intensiva de mano de obra, como es la zona rural de Goya, Lavalle y San Roque:

La emigración hacia otras zonas del país afecta a todos los departamentos de la provincia, aun a aquellos que tienen actividades más intensivas en mano de obra. Así, por ejemplo, Goya, en donde si bien el desarrollo tabacalero permite una mayor absorción de población productiva entre 1947-60, el estancamiento de este cultivo en el pasado decenio unido a la modalidad de producción existente, ha conducido a un fuerte proceso de emigración; para el período 1960-70, la tasa de crecimiento media anual fue de $8,2 \%$ que resulta inferior a la tasa de crecimiento vegetativo, estimada en $18 \%$, lo que pone en evidencia la emigración de fuertes contingentes. (Slutzky, 2001: 220).

Durante los años sesenta se afianzó un modelo de producción terrateniente que aumentó significativamente el número de hectáreas utilizadas pare el pastoreo; al igual que el número de ganado, esta concentración no generaba un proceso de mayor industrialización. Por otra parte, comienza a aparecer una variación en la matriz productiva con la aparición de la industria forestal. A inicios de 1960 no se registraba explotación forestal, mientras que para 1969 la provincia contaba con 31.478 hectáreas de forestación. Esta actividad contaba con fuertes estímulos estatales.

El siguiente cuadro muestra la evolución de las superficies explotadas de los cultivos más importantes durante la década de sesenta

\section{Superficie agrícola según tipo de cultivo. 1960. Corrientes}

\begin{tabular}{|c|c|c|c|c|c|c|c|c|}
\hline \multirow[t]{2}{*}{ Año } & \multicolumn{2}{|l|}{ Maíz } & \multicolumn{2}{|l|}{ Arroz } & \multicolumn{2}{|l|}{ Tabaco } & \multicolumn{2}{|c|}{ Algodón } \\
\hline & ha & $\%$ & ha & $\%$ & ha & $\%$ & ha & $\%$ \\
\hline 1960 & 44.911 & 21.5 & 29.206 & 14.2 & 19.315 & 9.2 & 31.889 & 15.0 \\
\hline 1969 & 40.000 & 19.0 & 41.852 & 20.0 & 18.261 & 8.5 & 14.896 & 7.1 \\
\hline \multirow[t]{2}{*}{ Año } & \multicolumn{2}{|l|}{ Yerba } & \multicolumn{2}{|l|}{ Citrus } & \multicolumn{2}{|l|}{ Otros } & \multicolumn{2}{|l|}{ Total } \\
\hline & ha & $\%$ & ha & $\%$ & ha & $\%$ & ha & $\%$ \\
\hline 1960 & 9.331 & 4.4 & 12.900 & 6.2 & 63.987 & 29.5 & 211.539 & 100.0 \\
\hline 1969 & 10.967(a) & 5.2 & 14.300(b) & 6.8 & 71.202 & 33.4 & 211.478 & 100.0 \\
\hline
\end{tabular}

Fuente: Slutzky, 2011 
Se puede observar el crecimiento del cultivo de arroz, así como la disminución de la producción de maíz, de tabaco, y la abrupta caída de la producción algodonera. En contrapartida, aumentó la producción en los yerbatales y los cultivos de cítricos.

La producción de los tabacaleros estaba en una situación de polaridad: por una parte existía una clase social de pequeños productores tabacaleros que no tenían una extensión superior a las cinco hectáreas; estos constituyen el $50 \%$ del total de los productores. Estos campesinos tienen que proletarizarse como mano de obra temporal para sobrevivir. La poca superficie de explotación propia explica el régimen de aparcería bajo el cual producían la mayor parte de estos productores tabacaleros, dejando hasta el $60 \%$ de la producción en manos de grandes propietarios que lograban ganancias con un escaso riesgo. Los productores con menos de cinco hectáreas solo llegaban a explotar el 1\% sobre el total de la superficie tabacalera provincial. Esta poca extensión de la tierra propia constituía una situación de subocupación para la familia campesina que se trasladaba como mano de obra temporaria en diferentes oficios rurales. Pero como era limitada la posibilidad de vender fuerza de trabajo porque generalmente las familias campesinas pobres están rodeadas de grandes campos sin mayores requerimientos laborales, la familia subsistía en base a cultivos como el maíz o la mandioca. Las condiciones de vida de este campesinado marginal que trabajaba pobremente su tierra y luego empleaba sus propias herramientas bajo el régimen de aparcería fue parte del conjunto de reclamos que esgrimirían las ligas agrarias.

A continuación, veremos un cuadro donde podemos ver con especificidad la situación del sector ganadero en la década que va del sesenta a los setenta a partir de un censo nacional agropecuario.

Explotaciones ganaderas clasificadas por número de cabezas. Vacunos, 1960-69.

\begin{tabular}{|c|c|c|c|c|c|c|c|c|}
\hline \multirow{3}{*}{$\begin{array}{l}\text { Número } \\
\text { cabezas }\end{array}$} & \multicolumn{4}{|c|}{1960} & \multicolumn{4}{|c|}{1969} \\
\hline & \multicolumn{2}{|c|}{ Explotaciones } & \multicolumn{2}{|c|}{ Cabezas } & \multicolumn{2}{|c|}{ Explotaciones } & \multicolumn{2}{|c|}{ Cabezas } \\
\hline & $\mathrm{N}^{\circ}$ & $\%$ & $N^{\circ}$ & $\%$ & $\mathrm{~N}^{\circ}$ & $\%$ & $\mathrm{~N}^{\circ}$ & $\%$ \\
\hline
\end{tabular}




\begin{tabular}{|c|c|c|c|c|c|c|c|c|}
\hline Hasta 100 & 14.743 & 84.0 & 337.002 & 11.7 & 15.459 & 81 & 374.223 & 9.5 \\
\hline De 101-400 & 1.569 & 8,9 & 318.698 & 11.0 & 1.945 & 10,2 & 402.664 & 10.1 \\
\hline De 401-1000 & 608 & 3,5 & 383.104 & 13.3 & 830 & 4.3 & 531.133 & 13.4 \\
\hline De 1001-4000 & 505 & 2,9 & 961.754 & 33.3 & 686 & 3.6 & 1.307.189 & 33.3 \\
\hline De 4001-10000 & 110 & 0,6 & 617.923 & 21.4 & 149 & 0.8 & 878.479 & 22.2 \\
\hline 10001 y más & 18 & 0,1 & 269.369 & 9.3 & 24 & 0.1 & 456.313 & 11.5 \\
\hline TOTAL & 17.553 & 100,0 & 2.887 .850 & 100.0 & 19.093 & 100.0 & 3.950.001 & 100.0 \\
\hline
\end{tabular}

Fuente, INDEC.

Lo que observamos en el cuadro es el avanzado grado de concentración de la producción ganadera; pero, como dijimos, esta no generaba un proceso de avance en la tecnificación e industrialización de la hacienda o de la carne.

En 1960 los ganaderos con más de 1000 cabezas concentran el 63\% del total de la hacienda vacuna, y en 1969 llegan a concentrar el 66\% del total. En este periodo es interesante observar que la fracción de los ganaderos que más crecen es la que cuenta con más de 10.000 cabezas, que pasa de tener 269.369 en 1960 a 456.313 en 1969. Esta fracción representa el 0,1\% del total de los productores. El mayor desarrollo de esta actividad se concentra en los departamentos del sudeste y la zona centro de la provincia.

\section{La lógica de la acumulación del sector rural en las últimas décadas}

En esta investigación sobre las variaciones en la acumulación en el territorio correntino realizamos un corte comparativo que va de la década de 60 a la actualidad, dada la intención de realizar una comparación que permita contrastar dos épocas muy diferentes del capitalismo a nivel mundial. En la actualidad, el régimen de acumulación flexible que caracteriza al capitalismo genera toda una reconfiguración de la formación social a escala global y nacional; es de suponer que esta también influye en la provincia de Corrientes. David Harvey plantea que el capital en esta nueva época circula a una mayor velocidad a la hora de efectivizar sus tasas de ganancia y de recomponer su lógica, identifica zonas vulnerables, ensambla y desensambla proyectos al unísono, depreda regiones productivas, valoriza fuerza de trabajo vulnerable, etc. (Harvey, 2005). 
Por otra parte, el corte comparativo entre los años sesenta y setenta en relación con la actualidad tiene que ver con la evolución de los censos nacionales agropecuarios (los informes saltan de 1960-1969 a 1988, y de allí al año 2002, y luego al 2008, por lo cual optamos por construir datos que parten del último censo de 2008 al presente, tarea que está en una etapa inicial).

En cuanto a lo que observamos de la última década -y la actualidad- del sector rural, podemos comenzar por decir que la actividad agropecuaria sigue siendo gravitante en la producción global de la provincia. Esta representa casi un tercio del PBG provincial en el año $2013 .^{2}$

El siguiente es un cuadro productivo del sector rural donde podemos observar, entre otras cosas, algunas de las mutaciones en la forma de acumulación en el territorio correntino en las últimas décadas. En principio, optamos por mostrar un pequeño cuadro que intenta dar cuenta de cierta continuidad en las formas de explotación agropecuarias (EAP) que veníamos observando en la década de sesenta. En algunos casos podemos ver una tendencia a la modernización en algunos sectores -el forestal y el arrocero-, y, en un grado relativo, en la ganadería.

Principales formas de acumulación en el sector rural en la actualidad.

\begin{tabular}{|l|l|l|l|}
\hline Tipo de actividad & No ha & Producción & $\begin{array}{l}\text { Concentración de la } \\
\text { propiedad }\end{array}$ \\
\hline Explotación arrocera & $\begin{array}{l}101.589 \\
(2013)\end{array}$ & 756.000 $(\mathrm{t})$ & $\begin{array}{l}\text { 76.000 has. } \\
\text { Corresponden a } \\
\text { establecimientos de más } \\
\text { de } 1.000 \text { has (Dos grandes } \\
\text { firmas) }\end{array}$ \\
\hline Exportación forestal & $\begin{array}{l}450.000 \\
(2012)\end{array}$ & $\begin{array}{l}1,4 \text { millones } \\
\text { toneladas }\end{array}$ & $\begin{array}{l}\text { densnacionales } \\
\text { trancentran más de la } \\
\text { mitad de la forestación. }\end{array}$ \\
\hline Explotación citrícola & $(2013)$ & $215.000(\mathrm{t})$ & $\begin{array}{l}\text { Pequeños y medianos } \\
\text { productores. } \\
\text { El } 48 \% \text { tiene un tamaño } \\
\text { menor a 10 has y un }\end{array}$ \\
\hline
\end{tabular}

\footnotetext{
2 Dirección Nacional de Relaciones Económicas con las Provincias . Disponible en URL:
} http://www2.mecon.gov.ar/hacienda/dinrep/Informes/archivos/corrientes.pdf Consultado: 6/7/2015. 


\begin{tabular}{|c|c|c|c|}
\hline & & & $43 \%$ entre 10 y 50 has \\
\hline Explotación yerbatera & 21.186 & $93.033(\mathrm{t})$ & $\begin{array}{l}\text { Una empresa concentra la } \\
\text { actividad. (grupo Las } \\
\text { Marías) }\end{array}$ \\
\hline $\begin{array}{l}\text { Explotación horticultura } \\
\text { (Tomate y Pimiento) }\end{array}$ & $\begin{array}{l}14.641 \\
(2010)\end{array}$ & $166.700(t)$ & $\begin{array}{l}\text { Medianos y grandes } \\
\text { productores bajo cubierta. }\end{array}$ \\
\hline Explotación tabacalera & $2.000(2014)$ & 7 millones de kg & 1.600 Productores \\
\hline Explotación Ganadera & $\begin{array}{l}\text { 6,4 millones } \\
\text { Año } 2002 \\
(5.017 .285 \\
\text { Cabezas }) \\
\text { Año } 2013\end{array}$ & $\begin{array}{l}900.000 \text { bovinos } \\
\text { (Básicamente terneros } \\
\text { para invernada) } \\
100.000 \text { cabezas se } \\
\text { faenan (Año 2014) }\end{array}$ & $\begin{array}{l}\text { Concentración. El } 8 \% \text { de } \\
\text { los productores tiene el } \\
63 \% \text { de los vacunos } \\
\text { (Año 2010). }\end{array}$ \\
\hline
\end{tabular}

Cuadro elaborado en base a fichas técnicas del INTA, INDEC, Dirección Nacional de Relaciones Económicas con las Provincias, Organizaciones empresariales del tabaco y el arroz y otras.

Lo que este cuadro muestra es una creciente tendencia a la concentración, concentración que por otra parte se conecta con la mayor presencia de capitales transnacionales que ejercen una violencia económica sobre las fracciones de la burguesía local que no pueden competir y se convierten en unidades económicas no rentables. Los grupos que comienzan a apropiarse de los negocios rurales tienen la capacidad de asimilar las reglas de juego de un régimen de acumulación flexible, combinando sus emprendimientos, valorizando mercancías en diferentes regiones del mundo, fijando precios, flexibilizando leyes laborales, etc. Esto es lo que podemos ver, por ejemplo, con los capitales extranjeros que compran estancias, forestan, o cultivan arroz en forma combinada.

Si observamos las diferentes actividades productivas podemos reconocer en la producción de arroz uno de los sectores más dinámicos de la burguesía en Corrientes. Algunas de las empresas que explotan la producción de arroz en Corrientes son Adecoagro -este grupo de siembra maneja casi 300.000 hectáreas entre Argentina, Brasil y Uruguay y tiene como uno de sus principales accionistas a George Soros.

Copra es otro de los grandes grupos económicos que explota el arroz en Corrientes. Tiene como uno de sus accionistas a Darío Aranda -Vicepresidente del Grupo Clarín. Actualmente, Copra S.A. es uno de los principales actores a nivel provincial y nacional en la producción de arroz, con más de 8.500 hectáreas plantadas en la localidad de Mercedes, ubicada en el centro de la 
provincia de Corrientes. Estos dos grupos hegemonizan la actividad. La producción arrocera se maneja hoy con una doble finalidad: abastecer al mercado interno es una, pero también buena parte de la producción tiene por destino la exportación. A su vez, en la actualidad el arroz es producido con el sistema de paquete tecnológico que tiene una semilla resistente a los químicos que permite una mayor velocidad en el cultivo.

Como pudimos observar en el cuadro anterior, el sector forestal adquiere fuerza. Ya en los años setenta, esta actividad comenzaba a marcar presencia como parte de la expansión mundial de una actividad que requería nuevas regiones a ser explotadas. El modelo de acumulación que se impone en este sector es el de alta concentración en la explotación del suelo. El caso paradigmático que podemos tomar es la transnacional Alto Paraná. Esta posee más de 200.000 hectáreas y ha desplazado a cientos de pobladores en la provincia de Misiones. En Corrientes, la Universidad de Harvard tiene 87.884 hectáreas en los Esteros del Iberá. Estas hectáreas son gestionadas a través de dos sociedades anónimas -Las Misiones S.A. y Evasa S.A. Estas se dedican a la plantación industrial de pinos y eucaliptus. Los beneficios económicos obtenidos por la producción y venta de madera se destinan a financiar parte de la actividad educativa de excelencia que promueve la casa de estudios norteamericana $^{3}$ (EVASA se autopromociona como una empresa verde). Bosques del Plata S. A., por su parte, es una empresa de capital chileno que explota la madera en la zona de Santo Tomé y Virasoro. Posee unas 65.000 hectáreas entre Misiones y Corrientes. Produce básicamente rollos, semillas y plantas de pino y madera. Corrientes y Misiones son las provincias más forestadas del país, concentran no menos del $70 \%$ del país. ${ }^{4}$ En consonancia con estas, se presenta una lista de otras ocho grandes sociedades comerciales que explotan a gran escala el monocultivo de árboles en Corrientes.

En una entrevista realizada a ingenieros agrónomos del INTA, estos comentaban su preocupación por el avance indiscriminado de la forestación como negocio a gran escala en la provincia. Entre otras cuestiones, se oponían a la interpretación errónea de considerar que ciertas zonas no boscosas

\footnotetext{
3 Ver por ejemplo el informe que aparece en INFO News sobre el avance de capitales extranjeros en el negocio de la forestación en la provincia de Corrientes. Harvard: la universidad tiene campos en Corrientes e incumple la ley. INFONwes. 9/10/2011)

Cfr. Datos obtenidos del primer inventario Forestal de la provincia de Corrientes. http://www.corrientes.gov.ar/portal/files/Informe\%20Final.pdf
} 
constituyen un ecosistema abierto a la implantación de árboles de cultivo. ${ }^{5}$ Ellos mencionaban que el hábitat se daña con la intensificación de un cultivo que destruye la biodiversidad de los ecosistemas. Un documental expone la particular forma en que la forestación afecta a los seres humanos y al ambiente, Cuando los arboles matan muestra por medio de un extenso informe cómo la provincia de Corrientes se ha convertido en un nicho para grandes grupos de inversión forestal, y el daño ambiental y humano que esto produce. No son pocas las comunidades que se han desplazado y los ambientes que comienzan a ser perjudicados por los agrotóxicos utilizados.

Los grandes grupos transnacionales que hegemonizan la producción forestal tienen, por otra parte, capacidad de condicionar los términos de contratación del personal, e incluso la presencia de los agentes de control estatal. La forestación es, claramente, un negocio que es auspiciado por las políticas estatales. En Corrientes, desde el año 2003 a la fecha, 1.611 forestadores recibieron unos 140 mil millones de pesos. En 2012, la provincia recibió unos 28 millones de pesos para 224 forestadores. Además, las empresas forestales, extranjeras o nacionales, poseen exención de impuestos, de ingresos brutos, estabilidad fiscal por 30 a 50 años y devolución anticipada del IVA, entre tantos otros beneficios fiscales. ${ }^{6}$

Si pasamos al sector ganadero encontramos que la ganadería vacuna y ovina ha experimentado una modernización relativa que no logra todavía transformar el escenario de producción extensiva de invernada. Los avances se dan en zonas puntuales y por parte de una minoría de estancieros que cuentan con el capital para reconvertir sus unidades productivas. La modernización del sector consiste básicamente en la implantación de pasturas, el manejo de rodeos por potreros, la alimentación con ciertos balanceados y la mejora genética, que permite sumar mayor cantidad de kilos en menos tiempo, al paso que se mejora la calidad de la carne. Las nuevas estancias generan también una suerte de profesionalización del empleo rural, pero estas demandan menos personal, aunque con mayor capacitación. El resto de los antiguos peones se presenta como un ejército sobrante.

El sector yerbatero es el que presenta el mayor grado de concentración de la propiedad. Un grupo, Las Marías, concentra casi el total de la producción en la provincia de Corrientes. La misma elabora yerba, acopia y procesa para 
otras plantas yerbateras de Misiones. Las condiciones laborales y de vida los taraferos es sumamente precaria.

Las condiciones de vida de los trabajadores rurales bajo cubierta del cultivo de pimiento, tomate y frutilla en la zona del Departamento Lavalle también es sumamente precaria. Las características de estos cultivos exigen un trabajo intensivo para lo cual hace ya varias décadas contratan no solo a personal de la zona, sino también a bolivianos que eran traídos especialmente para esta faena. Algunos de los principales productores de tomate de la localidad de Santa Lucía destacaban la predisposición al trabajo y la paciencia de los bolivianos, omitiendo la explotación que estos sufrían.

El sector citrícola tiene una mayor composición de pequeños y medianos productores que el de tomate y pimiento. Más allá de esto, se verifica una tendencia a la concentración de los establecimientos en los últimos tiempos. La producción de limón y naranja sufrió una etapa regresiva en los noventa y en la actualidad parece tener perspectivas de avanzar en un proceso de mayor industrialización en la región. De todas maneras, la tendencia a la disminución y desaparición de pequeños productores (menos de cinco hectáreas), es una constante, no por efecto de una competencia local, sino por las condiciones generales del mercado (altos costos, bajo precio, etc.). En cuanto al sector tabacalero, este se ha reducido drásticamente de los sesenta a la actualidad.

Las condiciones de vida y de trabajo de los productores tabacaleros estuvieron marcadas por un alto grado de explotación. Jornadas intensivas y bajos salarios fueron el denominador común para aquellos que eran parte de la masa de asalariados informales. Los pequeños productores propietarios, por su parte, en muchos casos no superaban la mera subsistencia. En número de productores, el sector se está contrayendo y de los 19000 productores que hubo en las mejores épocas, se han reducido a menos de 3000 productores, número que el IPT coloca en 2300 (Censo de productores 2012) y que algunos ya colocan en 1.500. Además del hecho de que muchos productores han dejado de producir, tampoco se ve una renovación generacional. En promedio, el productor está por encima de los 50 años. ${ }^{7}$

Luego de esta breve revisión de las diferentes características que presentan las ramas del sector rural, intentaremos arribar a una conclusión provisoria donde pondremos en juego la posibilidad de corroborar ideas previas y sintetizar el cuadro social que hemos indagado.

\section{Conclusión}

Noticias Agropecuarias 12/4/2014. 
¿Cómo interpretar este proceso de acumulación que hemos registrado en la provincia de Corrientes? ¿Estamos frente a la violencia sorda de las relaciones económicas que se basan en la contradicción capital-trabajo o podemos estar frente a formas de violencia extraeconómica, o formas de violencia por desposesión? Es interesante detenernos por un instante en una escena en particular: la de los pequeños productores algodoneros correntinos que explotaban una porción de tierra generalmente cedida sin costo. Estos verán disuelta parte de su economía familiar cuando el precio del algodón no permita que dicha escala productiva persista. Esta situación se reproduce en diferente grado con la producción del tabaco en la zona sudeste, y con la de naranja en diversas regiones. Los trabajadores rurales que se dedicaban a esta producción no eran asalariados formales; en su mayoría, eran pequeños productores que contaban con su familia como fuerza de trabajo. Los asalariados eran, por otra parte, temporarios. Los peones rurales, de hecho, se desplazan entre la chacra y las faenas ligadas a la cría del ganado, pero siempre como un empleo precarizado. Parte de esta masa marginal -como lo denominada José Nun (Nun, 2003)- es la que se ve desplazada hacia otras regiones, como vimos anteriormente.

Estaríamos así frente a una mixtura entre la violencia sorda del capital que somete a los sujetos a las reglas del mercado, la sujeción a la desocupación y el trabajo, como también la violencia extraeconómica que somete a zonas poco desarrolladas del capital, tal cual lo pensaba Rosa Luxemburg, del mismo modo que en esta época podemos considerar la existencia de procesos de acumulación y despojo, tal como lo analiza Harvey.

Las grandes plantaciones de arroz de Corrientes comparten dos características fundamentales: utilizan el paquete tecnológico transgénico y la producción se destina en gran parte a la exportación. Este modo de producir a lo ancho y largo del país cuenta con la connivencia de las autoridades gubernamentales. La producción arrocera no solo ha tendido a concentrarse a partir de grandes arroceras como COPRA y Adecoagro, sino que esta concentración está alterando fuertemente las condiciones de vida de la población por efecto de la contaminación y concentración de tierras que expulsa pobladores.

Como síntesis del modo de acumulación que emerge en el sector rural, hacemos alusión a la situación que viven los pobladores de los Esteros del Iberá, donde dos estancias de propietarios extranjeros, El tránsito y San Eugenio, se 
unieron para presionar a los pobladores de Yahabere, Ñu pi, Carambola y Plumero, para que abandonen sus tierras al cortar los caminos vecinales y estos no puedan circular.

Otro ejemplo de esto es el del empresario norteamericano Douglas Tompkins que compro cuatro estancias en la zona de los Esteros del lberá al grupo Pérez-Companc: Aña Cua, El Batel, El Tránsito, El Iberá. Entre las cuatro suman más de 60.000 hectáreas, que 'filantrópicamente' Tompkins protege. Antonio Lezcano, un poblador nacido y criado en la zona relata: "Desde que llegaron las forestales comenzaron a echar a quienes siempre vivieron acá", explica y precisa que en los últimos cinco años fueron expulsadas al menos 170 familias. "Desaparecieron parajes enteros", lamenta, y menciona más de diez, entre ellos Santa Bárbara, Montaña y Colonia San Antonio. ${ }^{8}$

Estas formas de desposesión probablemente se expandan. Esta violencia visible e invisible puede operar sobre muchos otros 'parajes' correntinos dada la forma que adquiere este territorio para los grupos de inversión global.

Este trabajo tiene como línea de continuidad el abordaje de los conflictos y protestas que se producen como modo de resistencia social en el territorio correntino.

\section{Bibliografía:}

- ALTHUSSER, Louis. BALIBAR, Etienne (1987). Para leer el capital. Trad. Marta Harnecker. Buenos Aires: Siglo XXI.

- DE ANGELIS, Massimo. Marx y la acumulación primitiva. El carácter continuo de los "cercamientos" capitalistas. En: Theomai N²6. Segundo semestre de 2012.

- ENGELS, Federico (1978). La revolución de la ciencia de Eugenio Duhring. El antiduhring. Moscú: Progreso.

- HARNECKER, Marta (2005). Conceptos elementales del materialismo histórico. Buenos Aires: Siglo XXI.

- HARVEY, David (2005). El nuevo imperialismo. Buenos Aires: CLACSO.

- LUCKACS, Gregory (1970). Historia y Conciencia de Clase. Trad. Francisco Duque. La Habana: Instituto del Libro.

- LUXEMBURG, Rosa (2011). La acumulación del capital. Madrid: Ediciones Internacionales Sedov.

- MARX, Karl, ENGELS, Federico (1974a). La ideología Alemana. Trad. Wenceslao Roces. Barcelona: Ediciones Pueblos Unidos y Ediciones Grijalbo.

$8 \quad$ Página 12 23/09/2013. 
- MARX, Karl y ENGELS, Federico (1974b). Carta de Engels a José Bloch. En: Obras Escogidas, en tres tomos. Moscú: Progreso.

- MARX, Karl (1974). Contribución a la crítica de la economía política. Trad. Marat Kuznetsov. Moscú: Progreso.

- MARK, Karl. (2005). El Capital, Tomo I. México D.F.: Siglo XXI.

- MARX, Karl. (1980). Teorías sobre la plusvalía II. Trad. Wenceslao Roces. México: Fondo de Cultura Económica.

- NUN, José. (2003). Marginalidad y exclusión social. Buenos Aires: Fondo de Cultura Económica.

- SAUTU, Ruth, BONIOLO, Paula, DALLE Pablo, ELBERT, Rodolfo (2005). Manual de metodología. Construcción del marco teórico, formulación de los objetivos y elección de la metodología. Buenos Aires. CLACSO.

- SLUTZKY, Daniel (2011). Estructura social agraria del nordeste de la Argentina: Desde la incorporación a la economía nacional al actual subdesarrollo concentrador y excluyente en la actualidad. Inédito. 